\title{
Pyramidal and Granule Cells Distribution through Hippocampal Fields: An Index for Sensory Information Processing
}

\author{
Abdoulaye Bâ \\ Université Félix Houphouët-Boigny, UFR Biosciences, Laboratoire de Neurosciences, Abidjan, Côte d’Ivoire \\ Email: Abdouba3000@hotmail.com
}

Received 23 January 2015; accepted 30 April 2015; published 6 May 2015

Copyright (C) 2015 by author and Scientific Research Publishing Inc.

This work is licensed under the Creative Commons Attribution International License (CC BY).

http://creativecommons.org/licenses/by/4.0/

(c) (i) Open Access

\begin{abstract}
Background: This work aims at investigating the histology of hippocampus formation as structural model of information processing. The study addressed the question whether the pattern of cellular type distribution within hippocampal fields could be used as support of information processing in the hippocampus. Method: Pyramidal-shaped neurons presenting both cytoplasm and nucleus outlined clearly were measured systematically on brain slides, using a light microscope connected to a microcomputer equipped with a scanner software for measuring particles. Morphological types of cells were identified following class sizes and their distribution determined through hippocampal fields. Results: A battery of statistical tests: Sturges' classification, class sizes distribution around overall mean, Bartlett's sphericity test, principal components analysis (PCA) followed by correlations matrix analysis and ANOVA allowed two cellular groups to be identified in the hippocampus: large and small pyramidal-shaped cells. Conclusion: The results show that sensory information processing in the hippocampus could be built on two classes of pyramidal neurons that differed anatomically with probably different physiological functions. The study suggests combination ensembles clustering large and small pyramidal cells at different rates, as fundamental signaling units of the hippocampus.
\end{abstract}

\section{Keywords}

Rat Hippocampus, Pyramidal and Granule Cells Distribution, Morphometric Measurements, Population Coding, Information Processing

\section{Introduction}

The comparatively simple architecture of the hippocampus formation has made it an attractive model for the

How to cite this paper: Bâ, A. (2015) Pyramidal and Granule Cells Distribution through Hippocampal Fields: An Index for Sensory Information Processing. Journal of Behavioral and Brain Science, 5, 173-184. 
elucidation of the structure and function of the cerebral cortex.

The most prominent rodent model of the hippocampus function was O'Keefe and Nadel's Theory of the hippocampus as mediating cognitive maps or neural representations of physical space. The notion of neural code in the hippocampus appeared firstly in the O'Keefe and Nadel's Theory, by the discovery of the hippocampal "place cells" coding physical space. These "place cells" are neighboring neurons that fire in association with a rat's place in the environment, independent of any particular stimulus or ongoing behavior [1] [2]. However neurophysiological findings showed that characteristic cells firing were found to be sensitive to modifications of both spatial and non-spatial stimuli [3]-[5]. For instance, cellular recording in the hippocampus showed that complex-spike neurons fire in relation to explicitly non-spatial (visual, auditory, olfactory and goal-directed movements) stimuli [6]-[8]. Thus there appeared the notion of dual tasking by hippocampal complex-spike cells, related to two different populations of neurons, one that codes place and another that codes the relationships between various environmental stimuli [9]. Later, studies have reported however, that there would be no systematic relationship between places in the environment and the anatomical details of the hippocampal structure. Rather the entire hippocampal network would participate in representing each significant aspect of space. Such a view conforms to the emerging computational view of distributed neural representation [10] [11]. The hippocampus function could better be described in terms of computational-representational activity, e.g., analyzing, synthesizing, comparing, storing, detecting and encoding the representations of different events [12]. The computational view of the hippocampus raises the question of neural code for the sensory information processing.

Recent advances in our understanding of information transfer suggest two candidate neural codes: Information is represented in the spike rate of neurons, or information is represented in the precise timing of individual spikes [13]. In the first model, cortical neurons must perform some sort of coincidence detection, such that a particular combination of presynaptic events leads to a postsynaptic spike [14]: Rate coding [15]. This combination requires an ensemble of 50 - 100 neurons representing the fundamental signaling units of cerebral cortex [16]. In the second model, it is postulated that the timing of spikes, their intervals and patterns can convey information: Temporal coding [17]. This hypothesis suggests that information may propagate via specific patterns of spikes, like Morse code or across neurons [17] [18].

This work aims at investigating hippocampus formation, one of the brain structures making up the limbic system, as structural model of information processing. Although the hippocampus lies beneath the cerebral cortex, it is not truly a subcortical structure in that it is really a cortical infolding itself. The structure is evolutionarily older and simpler (with fewer layered structures) than the surrounding neocortex, and is specified as archicortex [19]. The hippocampus-dependent spatial, temporal or emotional memory systems could have appeared early during evolution, having conserved their functional identity through vertebrate phylogenesis [20]. Phylogenic conservation of memory systems trough evolution raises the question of universal neural code. In addition, earlier studies indicate when the forebrain was removed, diencephalon continues to control through species, the well preserved stereotyped behaviors like mating rituals, predatory, defensive and maternal maneuvers [21]. The assumption is that information processing for those stereotyped behaviors achievement should be also preserved phylogenetically, based on the universality of neural code.

The concept that neural information is encoded in the firing rate of neurons has been the dominant paradigm in neurobiology for many years [22]. This paradigm has also been adopted by the theory of artificial neural networks. In rats, ensemble activity was recorded simultaneously from CA3 and CA1 in response to novel sensory cue configurations. Particularly, rate encoding in hippocampal CA3 cells ensembles is related to the acquisition and the expression of episodic memories [23]. According to Curto et al. (2013) [24] networks of neurons in the brain encode preferred patterns of neural activity via their synaptic connections. The full code can be accurately learned from a highly undersampled set of patterns. They find that binary patterns (neurons which turn "on" or "of", e.g. the neural code) are successfully stored in these networks, through their excitatory lateral connections. Binary coding suggests two contrasting modalities of cellular responses. Indeed, neurophysiological studies indicate two modalities of cellular responses recorded in CA3 pyramidal cells, expressed as burst-type firing cells (noisy) and non-burst-type firing cells (silent) [25]. In addition, following Xing and Gerstein [26], multi-sequential electrical stimulations of cortical neurons reveal also two different types of neuronal responses expressed as small and large receptive field. Immunocytochemical characterizations of neuron types identify two types of pyramidal cells in the stratum pyramidal, which exhibited different staining to calbindin and were predicted as large and small pyramidal cells (Szilágyi et al., 2011) [27]. However, these contrasting physiological 
and immunocytochemical properties of pyramidal cells responses were not strongly supported by any anatomical elements. Indeed, knowledge regarding the functional significance of the differences between these two pyramidal cell subtypes is lacking. Thus, despite the central importance of the rate coding, its underlying neural mechanisms remain unknown. In these studies we are seeking to identify anatomical components of neural coding and its consistency with the theory of transiently active cells assemblies. Descriptions of neuronal elements underlying such a code involve multiple disciplinary investigations. An aspect of these investigations was undertaken in this work and involved studying the histology of hippocampus formation in the rat: Distribution of morphological types of cells was assessed in different fields. The central problem is to build up a theory of information processing in the hippocampus, based on the cellular composition of various fields.

\section{Material and Methods}

\subsection{Subjects}

Nulliparous female Wistar rats, weighing 180 - 200 g, were housed individually in plastic cages $(27 \mathrm{~cm} \times 37 \mathrm{~cm}$ $\times 18 \mathrm{~cm}$ ) with the floor covered by wood-dust. A Wistar male was placed into each female's cage at $18.00 \mathrm{hr}$ daily. Presence of a vaginal plug indicated day 1 of gestation. Approximately 1 week prior to parturition, pregnant rats were checked daily in the morning for pups. At birth, each female nursed 10 pups from postnatal day (P) 10 to P21 corresponding to the weaning. The colony was bred in an aerated noiseless vivarium room subjected to diurnal daylight/night cycles, humidity $(75 \%)$ and ambient temperature $\left(25^{\circ} \mathrm{C} \pm 2^{\circ} \mathrm{C}\right)$. Ethical rules concerning in vivo experiments were observed in accordance with the guidelines of the U.S. Public Health Service and NIH regarding the care and use of animals for experimentation.

\subsection{Tissue Preparation}

On postnatal day 45, pups born from at least three females were pooled to minimize litter influence. Six pups were killed randomly by carotid incision. The brains were carefully removed, weighed and fixed in Bouin's fluid. Then, the brains were dehydrated by successive baths in alcohol solutions of increasing concentrations, followed by paraffin inclusion. Parasagittal sections, $10 \mu \mathrm{m}$ thick, started with the left hemisphere and traverse the left hippocampus. When the dentate gyrus of ventral hippocampus exhibited a well-rounded crest [28], then, a sample of 20 successive sections was taken on each brain for analysis. The sections were stained with a combination of haematoxylin-eosin (nucleus and cytoplasm staining respectively) and indigo carmine (nucleus staining in particular). The slides were observed under oil immersion $(1000 \times)$.

\subsection{Regions Analyzed}

In 45-day-old rats, the cells were scanned from pyramidal layer CA1-CA3, the hilar CA4 and the granular layer of dentate gyrus [29] (Figure 4(a)). Different subfields and cell types in the hippocampus were photomicrographed for anatomical illustrations [25] [30].

\subsubsection{Analysis of Cellular Types}

Identification of pyramidal-shaped neurons includes the presence of apical dendrite as depicted in Figure 3. That condition avoids interneurons and spherical cells to be recorded and presents theoretically the median profile of the cell. Cellular profiles analysis according to this criterion attenuated the biased effects provoked by cell cutting out of the center. All recognized pyramidal-shaped neurons with a visible apical dendrite, which present both cytoplasm and nucleus outlined clearly, were measured systematically. These conditions allowed sampling 55 neurons scarcely as N1. N1 sampling was used for cellular groups' identification following class sizes. For reliable measurements, the same cell has its cytoplasm and nucleus simultaneously recorded in N1 neurons. Nucleus whose cytoplasm was not clearly identified was ruled out for N1 sampling and for group identification. Only the cytoplasm-nucleus couples of the same cells were used for principal components analysis (N1 = 55 neurons) and cellular group identification.

\subsubsection{Analysis of Cellular Distribution}

Handling risks damage tissues and make indistinguishable the cytoplasm of the majority of neurons: Either 
cytoplasm staining was unsuccessful, or cytoplasm and nucleus were shredded by handling risks. Because nucleus was stained more successfully, which became more visible than the cytoplasm, cellular distribution was investigated by quantitative measurements of nuclear size throughout hippocampus formation [31]. These measurements take into account intervals of class sizes defined by N1 sampling. Each nucleus measurement which falls out of the interval of sizes defined by N1 sampling is discarded to avoid mitotic cells. Thus, 75 nuclei were measured per field CA1, CA3, CA4 and the dentate gyrus, and the total of 300 nuclei was sampled as N2.

\subsection{Cellular Measurements}

Cytoplasm and nucleus sizes of individual cells were measured on brain slides, using an Olympus Bx 40 light microscope equipped with a camera lucida which projects a virtual image on a digitizing tablet. A cursor, connected to a microcomputer and equipped with a laser, allowed outlining cellular morphologies seen through the ocular on the virtual image projected on the digitizing tablet. The distance run by the cursor on the virtual image was directly translated into real dimensions (in $\mu \mathrm{m}$ ) by a microcomputer, thanks to a scanner program for measuring particles [31]. The cells drawn by the laser of the cursor as their corresponding measurements were displayed simultaneously on the screen of the computer. Measurements of the cells were made on the microscope at $1000 \times$ and the computer was calibrated to the parameters of that magnification: Explicitly, the calibration showed $1 \mathrm{~cm}$ of the virtual image projected on the digitizing tablet corresponding to $6.17 \mu \mathrm{m}$ on the brain slide. Each nucleus scanned was marked with a pencil on the digitizing tablet to prevent either double measurement or errors of omission. For purposes of this study, the expression "size" indicated "circumference" of the nucleus and of the cytoplasm as well.

\subsection{Data Analysis}

Sturges' rule was performed on N1 data to determine intervals of nuclear sizes frequencies distribution; N2 sampling was used to assess class sizes distribution around overall mean [32]. The Bartlett's sphericity test was previously used to verify homogeneity of variances in N1 sampling. Some statistical tests, for example the analysis of variance or principal components analysis (PCA), assume that variances are equal across groups or samples. Equal variances across samples are called homoscedasticity or homogeneity of variances. The Bartlett's test can be used to verify that assumption and to demonstrate the applicability of PCA. Principal components analysis (PCA) was done on N1 sample (55 neurons): Three properties derived from each cell, e.g., cytoplasm and nucleus sizes, and the related cytoplasm/nucleus size ratio [33], undergo orthogonal projections on two factorial axes for any cellular group identification through clusters [34]. Between fields differences were tested using the one-way analysis of variance (ANOVA) to compare the mean nucleus size between different hippocampal fields. Differences between individual pairs of means were determined by Scheffé's F test for multiple comparisons [32].

\section{Results}

\subsection{Morphological Types of Cells throughout Hippocampus Formation}

Hippocampus pyramidal-shaped cells were scanned in the stratum pyramidale (fields CA3 and CA1), stratum granulosum (dentate granular layer), and in the hilar CA4 of Lorente de Nò [29]. Nucleus and cytoplasm sizes were systematically measured on each individual cell and their ratio calculated from N1 data (55 pyramidal-shaped neurons). Analysis of nuclear sizes frequencies distribution, using Sturges' classification on N1 data, yielded at least seven different class sizes (Table 1). The derived histogram showed two distinct peaks culminating respectively in class intervals of $23-27 \mu \mathrm{m}$ (group A) and $33-37 \mu \mathrm{m}$ (group B), (Figure 1). Thus, N1 data screening following Sturges' classification revealed two physically different groups of pyramidal-shaped cells.

Quantitative measurements of 300 nuclei throughout the hippocampus (75 nuclei recorded from each hippocampal field and sampled as N2) confirmed strongly two groups of pyramidal cells morphologically distinct. Sizes measurements on 300 nuclei averaged $30.05 \pm 0.58 \mu \mathrm{m}$. Distributions of class sizes around that overall mean $(30 \mu \mathrm{m})$ was analyzed using N2 data. It appears that nuclei sizes $<30 \mu \mathrm{m}$ correspond to the cellular group A, whereas nuclei sizes $\geq 30 \mu \mathrm{m}$ match the cellular group B. In group A, the average nuclear size was calibred as small; in group $\mathrm{B}$, the average nuclear size was calibred as large. 


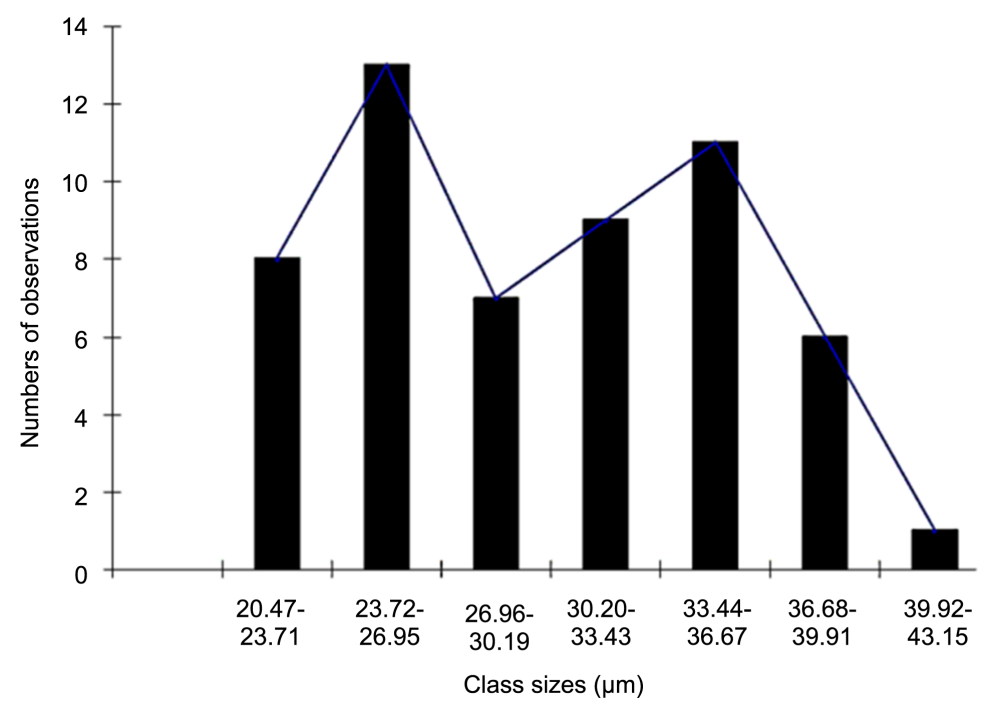

Figure 1. Histogram of nuclei frequencies distribution derived from Sturges' classification: the graph revealed two physically different groups of pyramidal cells.

Table 1. Sturges' classification of nuclei sizes. Sturges' classification performed on nuclear sizes ( $\mathrm{N}=55$ neurons $)$ allowed seven different class sizes to be identified.

\begin{tabular}{lcc}
\hline Classes & $\begin{array}{c}\text { Intervals of } \\
\text { nuclei sizes }(\boldsymbol{\mu m})\end{array}$ & Number of cells \\
\hline Class 1 & $20.47-23.71$ & 8 \\
Class 2 & $23.72-26.95$ & 13 \\
Class 3 & $26.96-30.19$ & 7 \\
Class 4 & $30.20-33.43$ & 11 \\
Class 5 & $33.44-36.67$ & 6 \\
Class 6 & $36.68-39.91$ & 1 \\
\hline
\end{tabular}

Using Bartlett's sphericity test, N1 sampling exhibited homogeneity and normal distribution of variances across groups $\mathrm{A}$ and $\mathrm{B}\left(\mathrm{Chi}^{2}=429.12 ; \mathrm{df}=5\right.$; determinant $\left.=3.538 \mathrm{E}-4 ; \mathrm{p}<0.0001\right)$ and then, $\mathrm{N} 1$ can be analyzed following PCA. Orthogonal projections on two factorial axes of 3 variables describing each pyramidal cell, e.g., nucleus and cytoplasm sizes and their ratio, using principal components analysis (PCA) on N1 data (matrix $=55$ neurons), allowed two cellular groups $\mathrm{A}$ and $\mathrm{B}$ to be identified efficiently through clusters, in the hippocampus (Figure 2). PCA provided for the principal axis (eigenvalue: 1.999, maximal variance: 66.637\%) and for the second axis (eigenvalue: 1.000, reamining variance: $33.356 \%$ ). The factorial weight of the nucleus was high on axis II (0.986) and weak on axis I (0.167), whereas the factorial weights of the cytoplasm and the cytoplasm/nucleus ratio were high on axis I (0.999 and 0.985 respectively) and weak on axis II (0.169 and 0.002 respectively). Table 2 shows correlations matrix resulting from statistical measure of the linear relationship between cell measurements. Nuclei sizes appeared to be significantly correlated with, neither cytoplasm sizes $(\mathrm{r}=$ $0.161, \mathrm{z}=1.161, \mathrm{p}=0.2458)$, nor cytoplasm/nucleus sizes ratio $(\mathrm{r}=-0006, \mathrm{z}=-0.041, \mathrm{p}=0.967)$. Conversely, there is a significant correlation between cytoplasm sizes and cytoplasm/nucleus sizes ratio $(r=0.986, z=$ 17.645, $\mathrm{p}<0.0001$ ). It appears that the variables nucleus and cytoplasm sizes are independent.

Table 3 indicates cellular measurements within groups A and B following PCA. In group A, cytoplasms and nuclei sizes averaged respectively $37.59 \pm 0.97 \mu \mathrm{m}$ and $25.07 \pm 0.66 \mu \mathrm{m}$ and their ratio was $1.51 \pm 0.05$. In group B, cytoplasms and nuclei sizes averaged $61.81 \pm 1.19 \mu \mathrm{m}$ and $34.85 \pm 0.78 \mu \mathrm{m}$ respectively, and their ratio 


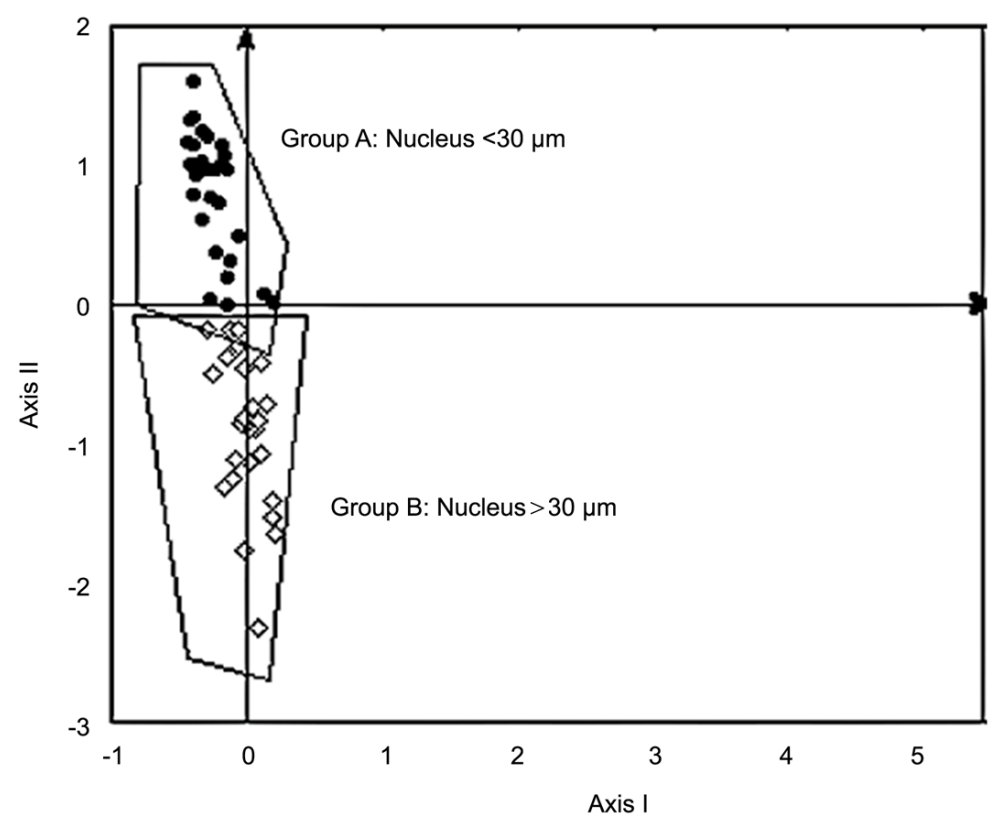

Figure 2. Principal component analysis (PCA) performed on 3 variables related to each pyramidal cell, e.g., nucleus and cytoplasm sizes and their ratio, allowed two cellular groups $\mathrm{A}(\bullet)$ and $\mathrm{B}(\diamond)$ to be identified efficiently through clusters, in the hippocampus: Group A was identified as small pyramidal cells (nucleus $<30 \mu \mathrm{m}$ ) and group B recognized like large pyramidal cells (nucleus $>$ $30 \mu \mathrm{m}) . \mathrm{N}=55$ neurons sampled.

Table 2. Correlation matrix for cells measurements. Values of $\mathrm{r}$ (correlation coefficient) resulting from pair-wise statistical comparisons of cellular parameters. $\mathrm{N}=54$ cells.

\begin{tabular}{cccc}
\hline & Nucleus size & Cytoplasm size & Cytoplasm/Nucleus ratio \\
\hline Nucleus size & 1.000 & 0.161 & -0.006 \\
Cytoplasm size & 0.161 & 1.000 & 0.986 \\
Cytoplasm/Nucleus ratio & -0.006 & 0.986 & 1.000 \\
\hline
\end{tabular}

Table 3. Hippocampus cellular groups. Principal components analysis indicated two different groups A and B corresponding to the small and large pyramidal cells respectively. Values are means \pm S.E.M. with number of cells shown in brackets.

\begin{tabular}{cccc}
\hline & \multicolumn{3}{c}{ Circumferences $(\boldsymbol{\mu m})$} \\
\hline Cellular groups & Cytoplasm & Nucleus & Cytoplasm/Nucleus ratio \\
\hline Average group A $(\mathrm{n}=28)$ & $37.59 \pm 0.97$ & $25.07 \pm 0.66$ & $1.51 \pm 0.05$ \\
Average group B $(\mathrm{n}=27)$ & $61.81 \pm 1.19^{\dagger}$ & $34.85 \pm 0.78^{\dagger}$ & $1.83 \pm 0.08$ \\
\hline
\end{tabular}

${ }^{\dagger} \mathrm{p} \leq 0.01$ vs. group A.

was $1.83 \pm 0.08$. Consequently, group A corresponds to the small pyramidal cells and group B represents the large pyramidal cells.

Subsequent analysis of N1 data in details, using an ANOVA, showed the mean nucleus size to be significantly different from the mean cytoplasm size $\left(F_{1,52}=146.838, \mathrm{p}<0.00001\right)$. Scheffé's post hoc test (p's $\left.<0.01\right)$ showed the cytoplasm to be significantly wider in large (group B) than in small (group A) pyramidal cells $\left(F_{1,52}=\right.$ 14.188). The same Post hoc test ( $<0.01)$ indicated the nucleus to be significantly bigger in large (group B) than in small (group A) pyramidal cells $\left(F_{1,52}=18.581\right.$ ). Interestingly, the cytoplasm of small pyramidal cells (group A) was 1.5 times wider than the nucleus; while in the large pyramidal cells (group B) the cytoplasm was 2 times wider than the nucleus (Table 3). Figure 3 showed a photomicrograph of large and small pyramidal cells. 


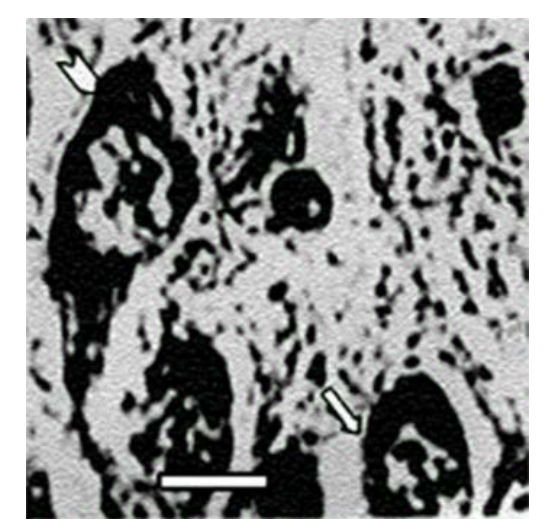

Figure 3. Light microscopy of cell types in the CA3: Large pyramidal cell (arrowhead) and small pyramidal cell (arrow). Bar $=10 \mu \mathrm{m}$.

\subsection{Cellular Size through Hippocampal Fields}

The mean nucleus size of the pyramidal cells has been assessed in dentate gyrus, CA1, CA3 and CA4 of Lorente de Nò [29], (Figure 4(a)). Nuclei sizes of the pyramidal cells (Table 4) averaged $26.84 \pm 0.36 \mu \mathrm{m}$ in dentate gyrus (Figure 4(b)), $30.58 \pm 0.58 \mu \mathrm{m}$ in CA4 (Figure 4(c)), $34.41 \pm 0.41 \mu \mathrm{m}$ in CA3 (Figure 4(d)) and $28.82 \pm$ $0.45 \mu \mathrm{m}$ in CA1 (Figure 4(e)). An ANOVA on the nuclei sizes of the pyramidal cells from the whole hippocampus showed a significant between-fields differences $\left(\mathrm{F}_{3,222}=48.383, \mathrm{p}<0.0001\right]$. Post hoc test $(\mathrm{p}<0.01)$ showed the mean nucleus size to be more voluminous in CA3 than in CA1 $\left(F_{1,148}=24.293\right)$, CA4 $\left(F_{1,148}=11.41\right)$ and dentate gyrus $\left(F_{1,148}=44.659\right)$. Although the mean nucleus size was slightly bigger in CA4 (30.58 \pm 0.58 $\mu \mathrm{m})$ than in CA1 $(28.82 \pm 0.45 \mu \mathrm{m})$, there was no significant difference between the two hippocampal fields $\left(F_{1,148}=2.405, \mathrm{p}>0.1\right)$. However, the mean nucleus size was significantly more voluminous in CA1 and CA4 than in dentate gyrus $\left(F_{1,148}=3.986, \mathrm{p}=0.05 ; F_{1,148}=10.922, \mathrm{p}<0.05\right.$ respectively].

\subsection{Cellular Distribution through Hippocampal Fields}

To determine the cellular composition, in terms of large (nuclei sizes $\geq 30 \mu \mathrm{m}$ ) and small (nuclei sizes $<30 \mu \mathrm{m}$ ) pyramidal cells within each hippocampal field, at least 75 nuclei were scanned in every field (Table 4). It appears that:

- The dentate gyrus was composed $19.76 \%$ by large pyramidal cells and $80.23 \%$ by small ones (Figure $4(\mathrm{~b})$ ).

- Field CA3 (Figure 4(d)) was made up 78.56\% of large pyramidal cells and $21.43 \%$ of small pyramidal cells.

- Field CA4 was formed $60.68 \%$ by large pyramidal cells and $39.31 \%$ by small ones (Figure 4(c)).

- Field CA1 contained $49.11 \%$ of large pyramidal cells and 50.89\% of small cells (Figure 4(e)).

\section{Discussion}

The present study investigates morphological identification of cellular types and determines their size and distribution throughout hippocampus formation. Four statistical tests: Sturges' classification, class sizes distribution around overall mean, PCA and ANOVA allowed two cellular groups to be identified in the hippocampus: large and small pyramidal cells.

These two cellular groups composed different fields as follows: dentate gyrus was made up with $80 \%$ of small and $20 \%$ of large pyramidal cells, while these proportions were inverted in the field CA3 where we noted about $79 \%$ of large and $21 \%$ of small pyramidal cells. Between these two extremes, CA1 field exhibited an intermediate composition with $49 \%$ of large and $51 \%$ of small pyramidal cells. CA4 had a cellular distribution similar to CA3. These results were confirmed by nuclei circumferences measurements. The mean nucleus size was calibrated as large in the field CA3 $(34.41 \pm 0.41 \mu \mathrm{m})$, medium in CA4 $(30.58 \pm 0.58 \mu \mathrm{m})$ and CA1 $(28.82 \pm 0.45$ $\mu \mathrm{m})$ and small in the dentate gyrus $(26.84 \pm 0.36 \mu \mathrm{m})$. According to cellular content, dentate gyrus and CA3 appear to be contrasted fields, relegating CA1 as a transitional intermediate field. Thus, the pattern of cellular distribution within hippocampal fields should be the support of information processing in the hippocampus. What neural code for the hippocampus built on its cellular composition? 

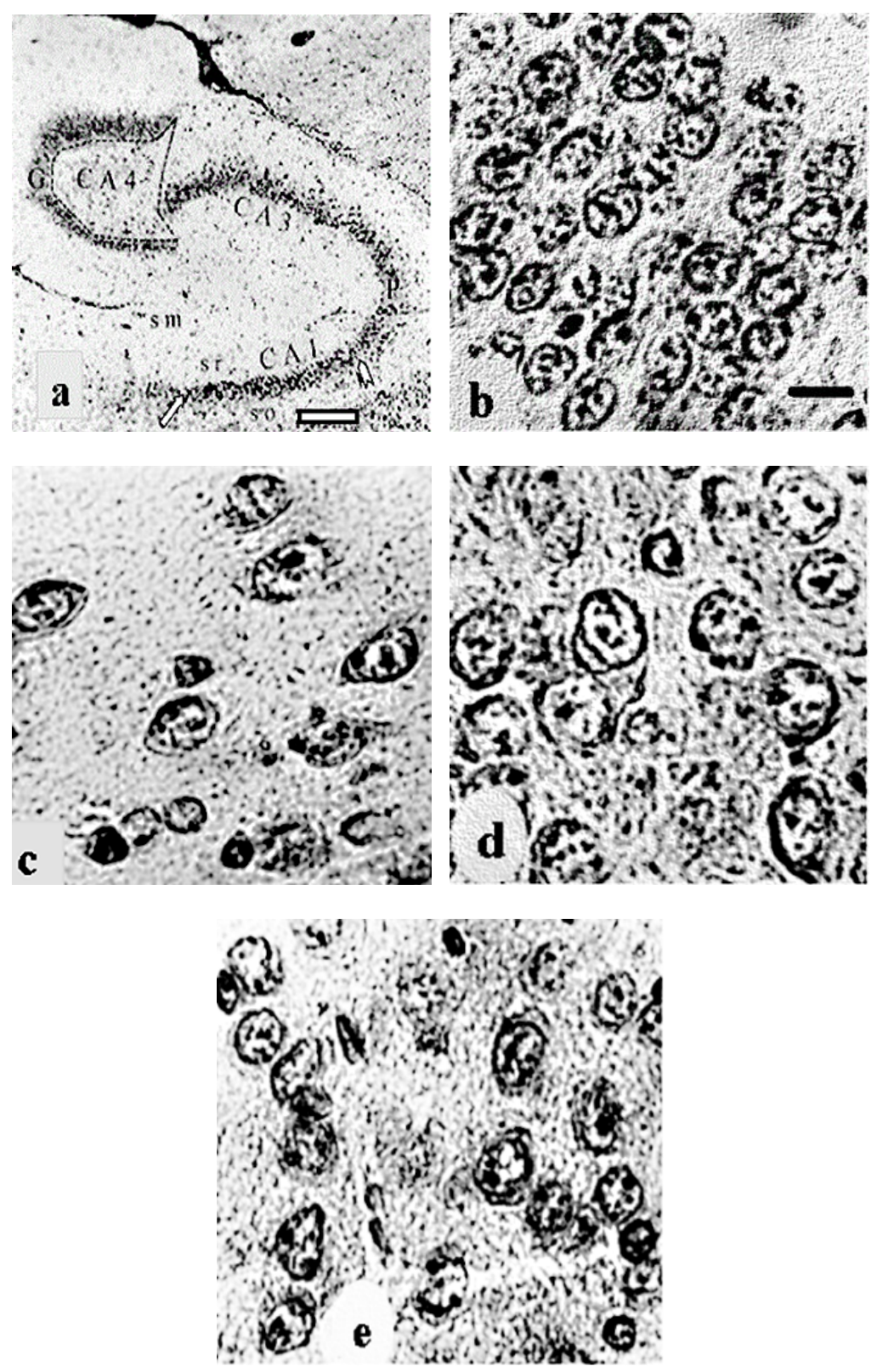

Figure 4. Parasagittal sections of the left ventral hippocampus in 45-day-old rats. Paraffin $10 \mu \mathrm{m}$ thick sections were stained with a combination of haematoxylin-eosin and indigo carmine; sections of the midtemporal hippocampus were assessed. (a) The arrowhead demarcates the CA3 region and the arrow denotes the CA1 region. Field CA4 is enclosed by broken lines [29]. Bar $=100 \mu \mathrm{m}$. (b) Dentate layer; (c) CA4; (d) CA3; (e) CA1. Bar = $10 \mu \mathrm{m}$. P: pyramidal cell layer; G: granule cell layer; sm: stratum moleculare; sr: stratum radiatum; so: stratum oriens.

Neurophysiological studies indicate two modalities of cellular responses recorded in CA3 pyramidal cells, expressed as burst-firing cells and non-burst-firing cells [24]. Masukawa et al. [35] reported in CA3 that $60 \%$ of pyramidal cells produced burst-type firing, when activated by the intracellular injection of a depolarizing current pulse, whereas the remaining cells (40\%) produced a non-burst-type firing [24]. The proportion of cells which generated bursts did not differ significantly through CA3 subregions and burst-type firing was related to great cell morphology [24]. Our results reported $79 \%$ of large pyramidal cells and $21 \%$ of small pyramidal cells in CA3. By analogy, the burst-type firing cells appear to be the large pyramidal cells e.g. "noisy neurons", while the non-burst-type firing cells seem to be the small pyramidal cells e.g. "silent neurons". Silent small neurons come into existence in the studies of Feng and $\mathrm{Li}$ [36] showing that the smaller the soma is, the more irregularly 
Table 4. Cellular size and distribution through hippocampal fields. In every field of the hippocampus, 75 pyramidal cells ( $\mathrm{N}=$ 75) are scanned at random to estimate the mean nucleus size by field (values were given as means \pm S.E.M.). Cellular composition was determined in percentage (\%) within each field as follows: Nucleus $<30 \mu \mathrm{m}=$ small cell; nucleus $>30 \mu \mathrm{m}=$ large cell. $\mathrm{N}=300$ cells sampled.

\begin{tabular}{|cccc|}
\hline & \multicolumn{2}{c|}{$\begin{array}{c}\text { Pyramidal cells distribution } \\
(300)\end{array}$} \\
\hline $\begin{array}{c}\text { Hippocampus } \\
\text { fields }\end{array}$ & $\begin{array}{c}\text { Mean nucleus size }(\mu \mathrm{m}) \\
(75)\end{array}$ & $\begin{array}{c}\text { Large cells } \\
(\%)\end{array}$ & $\begin{array}{c}\text { Small cells } \\
(\%)\end{array}$ \\
\hline $\begin{array}{c}\text { Dentate gyrus } \\
\text { CA4 }\end{array}$ & $26.84 \pm 0.36^{\dagger}$ & 19.76 & 80.23 \\
CA3 & $30.58 \pm 0.58^{\S}$ & 60.68 & 39.31 \\
CA1 & $34.41 \pm 0.41^{\ddagger}$ & 78.56 & 21.43 \\
\hline
\end{tabular}

${ }^{\dagger} \mathrm{p} \leq 0.05$ vs. all other groups. ${ }^{\S} \mathrm{p} \leq 0.05$ vs. dentate gyrus and CA3. ${ }^{\ddagger} \mathrm{p} \leq 0.01$ vs. all other groups.

the neuron fires. According to DeWeese et al. [37] neurons responses in auditory cortex can be described as a binary process: Neuron can signal the same stimulus with 0 or 1 action potential, independently of the shape or degree of dendritic ramification. These authors assume noisiness to be an inevitable feature of cortical codes. Deductive analyses suggest that noisy large neurons signal like binary code 1, while silent small neurons signal like binary code 0 . Furthermore, Shima and Tanji [38] found that neurons in monkey's motor area processed information in a binary-coded manner: They conclude on the interest to find neural elements operating in a binarycoded manner in the brain. Indeed, stimuli representations relating spatial place and episodic memory were decoded by different patterns of hippocampal activity and identified across multi-voxel pattern analysis [39]. This observation indicates that specific stimulus is encoded in pattern of activity which predicts the neural coding.

Our study proposed that sensory information processing in the hippocampus could be built on two classes of neurons that differed anatomically and functionally: Large and small pyramidal cells. The results support the theory of neuronal population coding based on firing rates [13]. This theory requires that information was transmitted in cerebral cortex, as rate codes, in ensembles cells combining 50 to 100 neurons as fundamental signaling units [16]. Similarly, our results suggest ensembles cells combining large and small pyramidal cells at different rates, as fundamental signaling units of the hippocampus. Thus, the message should be coded from summation of intrinsic currents deriving from both large and small pyramidal cells coactivated within simple or complex combinations. Osborne et al. [40] found that combinatorial codes based on patterns of spikes and silence are advantageous for representing stimulus information on short time scales, even when neurons have no complicated, stimulus-dependent correlation structure. Neuronal networks processed information through ensemble averages by an appropriate balance between inhibition and excitation [41].

Our present anatomical data strongly support neurophysiological findings of Xing and Gerstein [25]. These authors recorded neurons behavior in the cortical layer, after sequential stimulations and reported neurons to naturally assemble into functional groups, through their excitatory lateral connections, after sensory experience. Such groups are dynamic and amenable to change by input stimuli. For instance, the size of groups increases from 26 to 40 neurons, if excitatory density rings from 0.25 to 0.5 . Neurons coactivated within a group can be divided into two types, in accordance with their responses: 1) Weakly responding or silent neurons with a small receptive field; 2) strongly responding neurons with a large receptive field. Changing the sequence stimuli leads to large changes of groups and consequently to a new "allocation" of silent and strongly responding neurons [25]. From these observations, we can assume that anatomically large and small pyramidal cells should be ranked respectively like: 1) Strongly responding or noisy neurons with a large receptive field; 2) weakly responding or silent neurons with a small receptive field. Previous studies reported that sensory signal processing in cortical layer IV involves two major morphological classes of excitatory neurons: Spiny stellate and pyramidal cells [42]. Preferably the present study promotes the notion of small and large receptive field cells. Together, these observations suggest that the hippocampus processes sensory information with a precise neural code.

The computational model of sensory information processing built on cellular distribution through hippocampal fields generates different properties. 1) The rate of large and small pyramidal cells coactivated within signaling units should be determined by the nature and the intensity of the stimulus. This property has been shown by Xing and Gerstein [25], and gains further support in the findings of Kuhn [43] indicating that the output firing 
rate was controlled efficiently by the size of the input population. 2) Neural code should propagate linearly: From the former coding units there would be activation by vicinity between neurons of the same class within a field, probably through their excitatory lateral connections, resulting to the linear and integral transmission of the coded message. Linear propagation of rate coded information has been demonstrated in recent studies. Feinerman and Moses [44] investigated the ability of synchronous population activity in layered networks to transmit a rate code using a patterned one-dimensional hippocampus neuronal culture. The model exhibits population bursts that travel following efficient linear neural network. There is no rounding off of the signal: It keeps its characteristic form and propagates along the line [44]. The one-dimensional structure and anatomy of the culture induces causality in the propagation of the signal as each area excites its neighbor. The balance of excitatory and inhibitory synapses is crucial for that propagation [45]. Indeed, in vivo experiments showed that computation proceeds by direct pyramidal-pyramidal cell communication in the neocortex [46] and assemblies may transiently form [47]. Firing rate modulations are transmitted linearly through many layers in neocortex [48]. 3) The propagating code should be preserved: The rate of small and large pyramidal cells coactivated within a group should be sealed during linear progression in a given field. That property agrees with the theory of dynamic connectivity of cell-assembly: Propagating signals require formation of dynamic cell assemblies which necessitate dynamic spatiotemporal synaptic integration in cortical neurons [49]. It appears that the same neuron can participate in different cell assemblies suggesting a dynamic flexibility of cell-assembly during propagation [50]. For instance, Lin et al. [51] reported in CA1 that the network-encoding power derived from a set of functional coding units exhibiting "collective cospiking” dynamics. 4) The neural code should be re-coded: Since cellular composition varied with the field in our study, the proportion of large or small pyramidal cells coactivated within signaling units must vary with the field as well, suggesting variability of information processing from one field to the other. Following Kerr et al. [52] the active neuronal population constantly changes with time. Between-field variability of information processing was reported in CA3 and CA1, when ensemble activity was recorded simultaneously from CA3 and CA1 in rats exposed to two similar, novel environments [22]. A significant anatomical argumentation supporting between-field message re-coding in the hippocampus is provided by a considerable degree of convergence in the projection of the dentate gyrus upon the pyramidal cells of the fields CA3 and CA4 [53].

Our investigation on this computational model of archicortex suggests that inter species enigmatic conservation of memory systems and stereotyped behaviors through evolution should be based on the steadfastness and robustness of universal neural coding network. Neurophysiological and electrophysiological studies are needful to confirm these hypotheses advanced in our study. The major difficulty will be simultaneous intracellular recording of all the neurons co-activated within coding units [54].

\section{Acknowledgements}

Special thanks to Dr. Gervais N’Zi Konan and Dr. Siaka Berthé for statistical calculations.

\section{References}

[1] O’Keefe, J. and Nadel, L. (1978) The Hippocampus as a Cognitive Map. Oxford University Press, Oxford.

[2] O’Keefe, J.A. and Speakman, A. (1987) Single Unit Activity in the Rat Hippocampus during a Spatial Memory Task. Experimental Brain Research, 68, 1-27. http://dx.doi.org/10.1007/BF00255230

[3] Wible, C.G., Findling, R.L., Shapiro, M., Lang, E.J., Crane, S. and Olton, D.S. (1986) Mnemonic correlates of unit activity in the hippocampus. Brain Research, 399, 97-110. http://dx.doi.org/10.1016/0006-8993(86)90604-9

[4] Sakurai, Y. (1994) Involvement of Auditory Cortical and Hippocampal Neurons in Auditory Working Memory and Reference Memory in the Rat. The Journal of Neuroscience, 14, 2606-2623.

[5] Deadwyler, S.A., Bunn, T. and Hampson, R.E. (1996) Hippocampal Ensemble Activity during Spatial DelayedNonmatch-to-Sample Performance in Rats. The Journal of Neuroscience, 16, 354-372.

[6] Berger, T.W., Rinaldi, P., Weisz, D. and Thompson, R.F. (1983) Single-Unit Analysis of Different Hippocampal Cell Types during Classical Conditioning of Rabbit Nictitating Membrane Response. Journal of Neurophysiology, 50, 1197-1219.

[7] Young, B.J., Fox, G.D. and Eichenbaum, H. (1994) Correlates of Hippocampal Complex-Spike Cell Activity in Rats Performing a Nonspatial Radial Maze Task. The Journal of Neuroscience, 14, 6553-6563.

[8] Markus, E.J., Qin, Y.-L., Leonard, B., Skaggs, W.E., McNaughton, B.L. and Barnes, C.A. (1995) Interactions between 
Location and Task Affect the Spatial and Directional Firing of Hippocampal Neurons. The Journal of Neuroscience, 15, 7079-7094.

[9] Eichenbaum, H. and Cohen, N.J. (1988) Representation in the Hippocampus: What Do Hippocampal Neurons Code? Trends in Neurosciences, 11, 244-248. http://dx.doi.org/10.1016/0166-2236(88)90100-2

[10] McNaughton, B.L. and Morris, R.G.M. (1987) Hippocampal Synaptic Enhancement and Information Storage within a Distributed Memory System. Trends in Neurosciences, 10, 408-415. http://dx.doi.org/10.1016/0166-2236(87)90011-7

[11] Eichenbaum, H. (1996) Is the Rodent Hippocampus Just for “Place”? Current Opinion in Neurobiology, 6, 187-195. http://dx.doi.org/10.1016/S0959-4388(96)80072-9

[12] Schmajuk, N.A. (1984) Psychological Theories of Hippocampal Function. Physiological Psychology, 12, 166-183. http://dx.doi.org/10.3758/BF03332187

[13] Shadlen, M.N. and Newsome, W.T. (1994) Noise, Neural Codes and Cortical Organization. Current Opinion in Neurobiology, 4, 569-579. http://dx.doi.org/10.1016/0959-4388(94)90059-0

[14] Softky, W.R. and Koch, C. (1993) The Highly Irregular Firing of Cortical Cells Is Inconsistent with Temporal Integration of Random EPSPS. The Journal of Neuroscience, 13, 334-350.

[15] Shadlen, M.N. and Newsome, W.T. (1998) The Variable Discharge of Cortical Neurons: Implications for Connectivity, Computation, and Information Coding. The Journal of Neuroscience, 18, 3870-3896.

[16] Zohary, E., Shadlen, M.N. and Newsome, W.T. (1994) Correlated Neuronal Discharge Rate and Its Implications for Psychophysical Performance. Nature, 370, 140-143. http://dx.doi.org/10.1038/370140a0

[17] Richmond, B. and Optican, L. (1990) Temporal Encoding of Two-Dimensional Patterns by Single Units in Primate Primary Visual Cortex. II. Information Transmission. Journal of Neurophysiology, 64, 370-380.

[18] Engel, A., Konig, P., Kreiter, A., Schillen, T. and Singer, W. (1992) Temporal Coding in the Visual Cortex: New Vistas on Integration in the Nervous System. Trends in Neurosciences, 15, 218-226. http://dx.doi.org/10.1016/0166-2236(92)90039-B

[19] Amaral, D. and Lavenex, P. (2006) Hippocampal Neuroanatomy. In: Andersen, P., Morris, R., Amaral, D., Bliss, T. and O’Keefe, J., Eds., The Hippocampus Book, Oxford University Press, Oxford, 37-115.

[20] Broglio, C., Gómez, A., Durán, E., Ocaña, F.M., Jiménez-Moya, F., Rodríguez, F. and Salas, C. (2005) Hallmarks of a Common Forebrain Vertebrate Plan: Specialized Pallial Areas for Spatial, Temporal and Emotional Memory in Actinopterygian Fish. Brain Research Bulletin, 66, 277-281. http://dx.doi.org/10.1016/j.brainresbull.2005.03.021

[21] Lonstein, J. and Stern, J.M. (1997) Role of the Midbrain Periaqueductal Gray in Maternal Nurturance and Aggression: C-fos and Electrolytic Lesion Studies in Lactating Rats. The Journal of Neuroscience, 17, 3364-3378

[22] Ponulak, F. and Kasinski, A. (2011) Introduction to Spiking Neural Networks: Information Processing, Learning and Applications. Acta Neurobiologiae Experimentalis, 71, 409-433.

[23] Leutgeb, S., Leutgeb, J.K., Moser, E.I. and Moser, M.B. (2006) Fast Rate Coding in Hippocampal CA3 Cell Ensembles. Hippocampus, 16, 765-774. http://dx.doi.org/10.1002/hipo.20201

[24] Curto, C., Degeratu, A. and Itskov, V. (2013) Encoding Binary Neural Codes in Networks of Threshold-Linear Neurons. Neural Computation, 25, 2858-2903. http://dx.doi.org/10.1162/NECO_a_00504

[25] Bilkey, D.K. and Schwartzkroin, P.A. (1990) Variation in Electrophysiology and Morphology of Hippocampal CA3 Pyramidal Cells. Brain Research, 514, 77-83. http://dx.doi.org/10.1016/0006-8993(90)90437-G

[26] Xing, J. and Gerstein, G.L. (1996) Networks with Lateral Connectivity. II. Development of Neuronal Grouping and Corresponding Receptive Field Changes. Journal of Neurophysiology, 75, 200-216.

[27] Szilágyi, T., Orbán-Kis, K., Horváth, E., Metz, J., Pap, Z. and Pávai, Z. (2011) Morphological Identification of Neuron Types in the Rat Hippocampus. Romanian Journal of Morphology and Embryology, 52, 15-20.

[28] Bayer, S.A. (1980) Development of the Hippocampal Region in the Rat I. Neurogenesis Examined with 3H-Thymidine Autoradiography. Journal of Comparative Neurology, 190, 87-114. http://dx.doi.org/10.1002/cne.901900107

[29] Lorente de Nò, R. (1934) Studies on the Structure of the Cerebral Cortex II. Continuation of the Study of the Ammonic System. Journal für Psychologie und Neurologie, 46, 113-177.

[30] Bâ, A., Seri, B.V., Aka, K.J., Glin, L. and Tako, A. (1999) Comparative Effects of Developmental Thiamine Deficiencies and Ethanol Exposure on the Morphometry of the CA3 Pyramidal Cells. Neurotoxicology and Teratology, 21, 579-586. http://dx.doi.org/10.1016/S0892-0362(99)00014-8

[31] Bâ, A., N’Douba, V., d’Almeida, M.A. and Seri, B.V. (2005) Effects of Maternal Thiamine Deficiencies on the Pyramidal and Granule Cells of the Hippocampus of Rat Pups. Acta Neurobiologiae Experimentalis, 65, 387-398.

[32] Wayne, W.D. (1987) Biostatistics: A Foundation for Analysis in the Health Sciences. 4th Edition, John Wiley \& Sons, Hoboken. 
[33] Barrett, P.T. and Kline, P. (1981) The Observation to Variable Ratio in Factor Analysis. Personality Study \& Group Behaviour, 1, 23-33.

[34] Gorusch, R.L. (1983) Factor Analysis. 2nd Edition, Lawrence Erlbaum Associates, Hillsdale, New Jersey.

[35] Masukawa, L.M., Benardo, L.S. and Prince, D.A. (1982) Variations in Electrophysiological Properties of Hippocampal Neurons in Different Subfields. Brain Research, 242, 341-344. http://dx.doi.org/10.1016/0006-8993(82)90320-1

[36] Feng, J.F. and Li, G.B. (2002) Impact of Geometrical Structures on the Output of Neuronal Models: A Theoretical and Numerical Analysis. Neural Computation, 14, 621-640. http://dx.doi.org/10.1162/089976602317250924

[37] DeWeese, M.R., Wehr, M. and Zador, A.M. (2003) Binary Spiking in Auditory Cortex. The Journal of Neuroscience, 23, 7940-7949.

[38] Shima, K. and Tanji, J. (2006) Binary-Coded Monitoring of a Behavioral Sequence by Cells in the Pre-Supplementary Motor Area. The Journal of Neuroscience, 26, 2579-2582. http://dx.doi.org/10.1523/JNEUROSCI.4161-05.2006

[39] Chadwick, M.J., Bonnici, H.M. and Maguire, E.A. (2012) Decoding Information in the Human Hippocampus: A User's Guide. Neuropsychologia, 50, 3107-3121. http://dx.doi.org/10.1016/j.neuropsychologia.2012.07.007

[40] Osborne, L.C., Palmer, S.E., Lisberger, S.G. and Bialek, W. (2008) The Neural Basis for Combinatorial Coding in a Cortical Population Response. The Journal of Neuroscience, 28, 13522-13531. http://dx.doi.org/10.1523/JNEUROSCI.4390-08.2008

[41] Bonifazi, P., Ruaro, M.E. and Torre, V. (2005) Statistical Properties of Information Processing in Neuronal Networks. European Journal of Neuroscience, 22, 2953-2964. http://dx.doi.org/10.1111/j.1460-9568.2005.04464.x

[42] Schubert, D., Kötter, R., Zilles, K., Luhmann, H.J. and Staiger, J.F. (2003) Cell Type-Specific Circuits of Cortical Layer IV Spiny Neurons. The Journal of Neuroscience, 23, 2961-2970.

[43] Kuhn, A., Aertsen, A. and Rotter, S. (2003) Higher-Order Statistics of Input Ensembles and the Response of Simple Model Neurons. Neural Computation, 15, 67-101. http://dx.doi.org/10.1162/089976603321043702

[44] Feinerman, O. and Moses, E. (2006) Transport of Information along Unidimensional Layered Networks of Dissociated Hippocampal Neurons and Implications for Rate Coding. The Journal of Neuroscience, 26, 4526-4534. http://dx.doi.org/10.1523/JNEUROSCI.4692-05.2006

[45] Feinerman, O., Segal, M. and Moses, E. (2005) Signal Propagation along Unidimensional Neuronal Networks. Journal of Neurophysiology, 94, 3406-3416. http://dx.doi.org/10.1152/jn.00264.2005

[46] Holmgren, C., Harkany, T., Svennenfors, B. and Zilberter, Y. (2003) Pyramidal Cell Communication within Local Networks in Layer 2/3 of Rat Neocortex. The Journal of Physiology, 551, 139-153. http://dx.doi.org/10.1113/jphysiol.2003.044784

[47] Katz, D.B., Simon, S.A. and Nicolelis, M.A.L. (2002) Taste-Specific Neuronal Ensembles in the Gustatory Cortex of Awake Rats. The Journal of Neuroscience, 22, 1850-1857.

[48] Van Rossum, M.C.W., Turrigiano, G.G. and Nelson, S.B. (2002) Fast Propagation of Firing Rates through Layered Networks of Noisy Neurons. The Journal of Neuroscience, 22, 1956-1966.

[49] Azouz, R. (2005) Dynamic Spatiotemporal Synaptic Integration in Cortical Neurons: Neuronal Gain, Revisited. Journal of Neurophysiology, 94, 2785-2796. http://dx.doi.org/10.1152/jn.00542.2005

[50] Maurer, A.P., Cowen, S.L., Burke, S.N., Barnes, C.A. and McNaughton, B.L. (2006) Organization of Hippocampal Cell Assemblies Based on Theta Phase Precession. Hippocampus, 16, 785-794. http://dx.doi.org/10.1002/hipo.20202

[51] Lin, L., Osan, R., Shoham, S., Jin, W., Zuo, W. and Tsien, J.Z. (2005) Identification of Network-Level Coding Units for Real-Time Representation of Episodic Experiences in the Hippocampus. Proceedings of the National Academy of Sciences USA, 102, 6125-6130. http://dx.doi.org/10.1073/pnas.0408233102

[52] Kerr, J.N.D., Greenberg, D. and Helmchen, F. (2005) Imaging Input and Output of Neocortical Networks in Vivo. Proceedings of the National Academy of Sciences USA, 102, 14063-14068. http://dx.doi.org/10.1073/pnas.0506029102

[53] Schlessinger, A.R., Cowan, W.M. and Gottlieb, D.I. (1975) An Autoradiographic Study of the Time of Origin and the Pattern of Granule Cell Migration in the Dentate Gyrus of Rat. Journal of Comparative Neurology, 159, 149-175. http://dx.doi.org/10.1002/cne.901590202

[54] Ortega, G.J., Bongard, M., Louis, E. and Fernández, E. (2004) Conditioned Spikes: A Simple and Fast Method to Represent Rates and Temporal Patterns in Multielectrode Recordings. Journal of Neuroscience Methods, 133, 135-141. http://dx.doi.org/10.1016/j.jneumeth.2003.10.005 